$\pm$

DRILIING-INDUCED BOREHOLE-WALL DAMAGE

AT SPENT FUEL TEST-CLIMAX

SPENI FUEL IEST-CLIM

H. C. Weed

W. B. Durham

December 1982

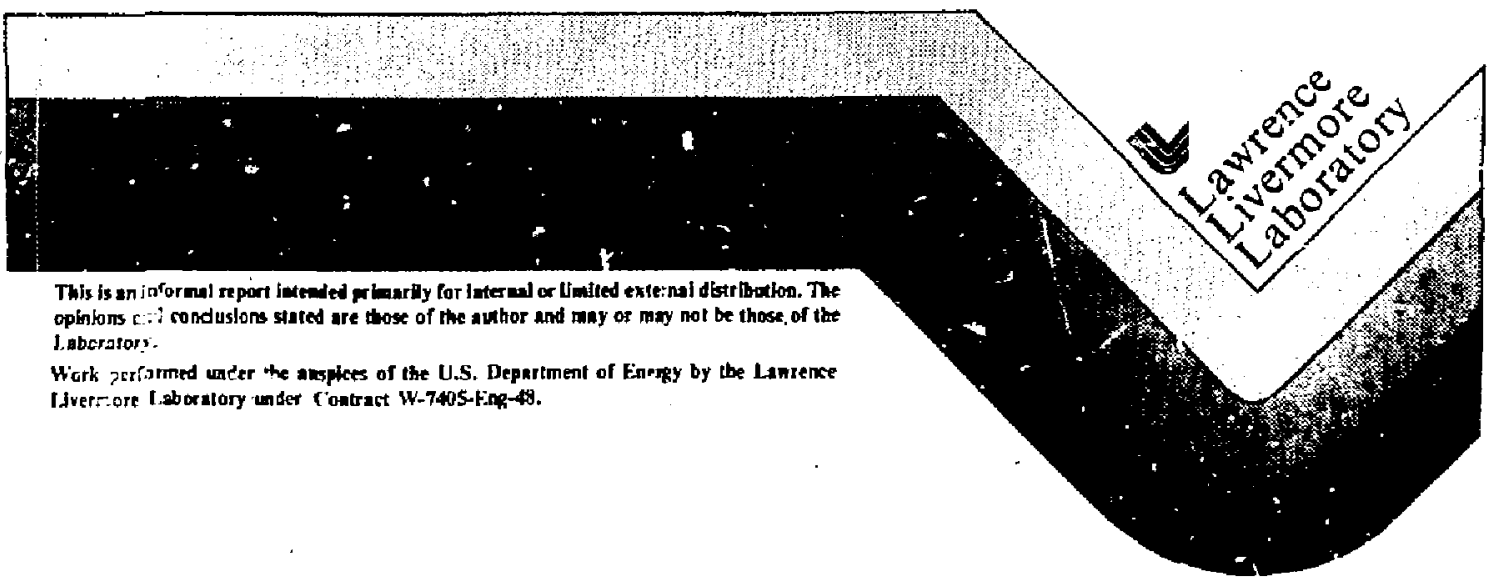




\section{DRILLING-INDUCED BOREHOLE-WALL DAMAGE AT SPENT FUEL TEST-CLIMAX}

by

H. C. Weed and W. B. Durham

UCID- -19672

0053005417

\section{ABSTRACT}

Microcracks in a sample of quartz monzonite from the Spent Fuel Test-climax were measured by means of a scanning electron microscope in order to estimate the background level of damage near the borehole-wall. It appears that the hammer-drilling operation used to create the borehole has caused some microfracturing in a region 10 to $30 \mathrm{~mm}$ wide around the borehole. Beyond $30 \mathrm{~mm}$, the level of microfracturing cannot be distinguished from background.

\section{INTRODUCTION}

Heat and fluid transport properties of the rock are important in long-term subsurface storage of nuclear fuel. Since these and the mechanical strength are usually a result of changes in microcrack and crack structure, it is desirable to measure the structure directly and attempt to quantify it. This study is one of several laboratory studies undertaken to assist in the interpretation of field test results from the Spent Fuel Test-Climax (SFT-C) at Nevada Test Site (Ramspott et al. 1979). It is intended to provide a measure of the background or reference level of damage in the vicinity of the hammer-drilled boreholes in which the waste canisters are stored, so that the later effects of heat, radiation, etc., may be more clearly defined. A particular aim of this study is to determine the effect which hammer-drilling has had on the reference damage level.

$2046 x$

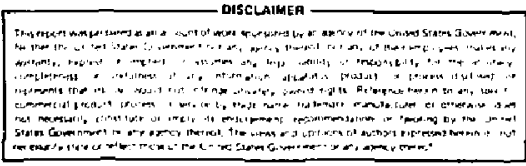




\section{EXPERIMENTAL WORK}

\section{Sample Preparation and Microscopy.}

The rock studied comes from the quartz monzonite portion of the Climax stock at NTS. Izett (1960) has described its mineralogy and petrology. Starting material came from core HDD-2 which had been drilled tangent to waste canister borehole CEH-18, $(610 \mathrm{~mm}$ diameter), so that part of the core surface was the original borehole surface. The borehole was located at Station $1+22.89 \mathrm{~m}$ from the bottom of the shaft U1 5-01, and the top of the borehole collar was located at $1117.7 \mathrm{~m}$ above mean sea level. The core was $140 \mathrm{~mm}$ diameter $\times 5.02 \mathrm{~m}$ length. The surfaces examined in this study lay in a single horizontal plane located roughly $20 \mathrm{~mm}$ from the bottom end of the $5.02 \mathrm{~m}$-long core. Individual sections intended for scanning electron microscope (SEM) observation, were cored at the locations shown in Fig. J. The sections were marked to orient them with respect to the location of the original borehole. The sections were cut on a diamond saw to a thickness of $5 \mathrm{~mm}$, and approximately $1 \mathrm{~mm}$ was rough ground from the face of interest in order to remove cutting damage. They were then polished with abrasive paper and finished with 2- $\mu \mathrm{m}$ alumina on a cloth lap. The polished surfaces were next ion-milled in order to remove the thin layer which had been smeared and damaged by the polishing procedure. After ion milling, samples ware coated with - thin layer of carbon by high-vacuum evaporation, to increase surface conductivity and prevent static charge accumulation under electron bombardment in the SEM. 
The SEM used was an AMR 1000 equipped with a Kevex Micro-X 7000 analytical spectrometer used for identification of the mineral phases. The SEM was operated in the backscattered (reflected) electron mode; the electron beam accelerating potential was 20 keV, working distance $12 \mathrm{~mm}$, and sample tilt $30 \mathrm{deg}$. Micrographs were taker; at a magnification of $500 \mathrm{X} \pm 10 \%$ at preselecied locations along traces which were parallel to the wall of the original borehole (Fig. 1). Eight to nine usable micrographs resulted from each scan and two scans were made for each section. Starting points were at least $1 \mathrm{~mm}$ from the section edge, and the $2 \mathrm{~mm}$ intervals were maintained strictly from stage control vernier settings. Two micrographs were made at each location, one for crack measurements, and the other to record the mineral phases. The crack images on the micrographs constitute the raw data for the study.

\section{Fracture Measurement.}

For at least as long as the SEM has been used to study the physical appearance of rock surfaces (Brace et al., 1972) the term "Crack" has been used to describe the non-equant physical discontinuity one observes on almost any rock surface. (The more equant discontinuity is called a "pore"). The same terminology is used in this paper.

The crack measurement procedure consisted of three steps:

(1) Operator discrimin.. son of fresh cracks;

(2) Digitization of the discriminated crack pattern;

(3) Numerical analysis of the digitized image. 
The first step required some subjective operator decisions to discriminate pre-existing cracks from "fresh" cracks introduced by operations associated with SFT-C. Fig. 2 shows some typical SEM micrographs. A crack was usually judged on the basis of ph'sical appearance: a sharply defined edge and pieces which fit together marked an obvious fresh crack; a crack which intersected many pores and had a varying width along its trace or which was partially filled with material fixed to the crack walls was obviously pre-existing. A full spectrum of cracks existed, grading from obviously fresh to obviously pre-existing. The fresh vs. old decision was made exclusively by one of us (WBD) and as much effort as possible was made to shield the data from being systematically affected by day-to-day variations in mental attitude. In particular, when the operator measurements were made (see below), the identity of the micrographs was masked and the order of measurement was randomized by shuffling the micrographs.

Step (2) was accomplished by making pencil tracings of the fresh cracks on transparent, matte-finish overjays, one micrograph at a time, then photocopying the overlays on white paper to produce an unambiguous black on white image of the cracks. The photocopied image was then digitized and analyzed with a Quantimet 700 image analyzer. By an operator-invoked convention within the image analyzer, two intersecting cracks were counted as two cracks. Output from the image analyzer consisted of a list of cracks along with their areas, perimeters, and locations. Since all cracks had been forced to have the same width (the width of a pencil trace), the area and perimeter information were combined to give a single parameter, length.

Step (3) was a simple matter of transferring the image analyzer lists to a computer, combining the lists into one large table, and deriving the desired information from the large table. Extensive use was made of the Livermore Time Sharing System data Management program FRAMIS (Jones at ai., 1981). 


\section{RESULTS}

Six hundred seventy-four fresh cracks were measured in 88 micrographs taken of the $6 \mathrm{SEM}$ samples. From the Jength and location data tabulated by the image analyzer, the following parameters were extracted and plotted as a function of radial distance from the axis of the $610 \mathrm{~mm}$ borehole:

$x \equiv \quad$ average length of individual cracks in each section (Fig. 3; Table 1)

$\mathrm{n}=$ average number of cracks per unit area for each section (Fig. 4; Table 2)

$L \equiv \quad$ average total crack length per unit area for each section (Fig. 5; Table 3)

$\overline{\ln (Q)}=$ the average of the logarithm of the length of individual cracks for each section (Figs. 6; Table 4)

The data of Fjgs. 4 and 5 reveal a clear dependence of the parameter $n$ upon which operator took the SEM micrographs. For this reason, all data and parameters derived therefrom are retained in two sets (Set 1:WBD; Set $2: \mathrm{HCW}$ ). It is unlikely that the bias was generated during the crack measurement step because, as indicated above, the micrographs were shuffled, masked as to their identity, and measured by only one of the authors. It is also unlikely that the effect really exists in the rock samples. The remaining possibility is that there was a difference in operating conditions of the SEM at the times when the two sets of micrographs were taken. Statistical analysis by means of prcbability plots (Wilk and Gnanadesikan, 1968) shows that the average crack length ( $(2)$ is log-normally distributed for each set considered separately (Figs. 7(a), (b)). Analysis also shows that $\mathrm{n}$ is not normally or log-normally distributed. The distributions for $\mathrm{n}$ and for $L$ were not identified since the results for $\ln (\ell)$ appeared to provide an adequate 
description of the trends in the data. Tables 1 to 3 do not give standard deviations for $\ell$, $\mathrm{n}$, and $\mathrm{L}$ since these could not be calculated without either knowing or else assuming the form of the distribution functions. Further analysis of $\overline{\ln (l)}$ shows that the Set 1 and the Set 2 data pertaining to section 2 sample the same crack pojulation. The same situation exists for section 6, but not for section 3. Section 3 shows a significantly smaller mean and standard deviation for Set 1 than for Set 2 . This may be due to a change in the distribution function along the two traces in section 3. There were insufficient data for a similar analysis on section 4.

\section{DISCUSSION}

A consistent trend in Figs. 3 to 6 is that sections 1 and $2610 \pm 3 \mathrm{~mm}$ from the borehole wall) have more and longer cracks than the others. Results for the other sections are less clear for Set 1 , but for Set 2 the general trend is toward lower values for all the parameters with increasing distance from the borehole wall. Figure 8 dispels the likelihood that the cracks formed as a result of perturbation of the in situ stress field by the presence of the $610-\mathrm{mm}$ borehole. The elastic solution ( $R$. Thorpe, 1982) shows that tensional stresses do not exceed $\perp \mathrm{MPa}$ and that stress differences never exceed a few $\mathrm{MPa}$. Also, cracks were probably not caused by the coring operation on the $140-\mathrm{mm}$ core since section 5, which intersects the outer diameter of the core, shows generally lower parameter values than sections 1 and 2. Therefore, the hammer-drilling operation remains as the probable cause of the high values of the crack parameters observed in sections 1 and 2 . 
No measure was made in this study of the background number and length of "fresh" cracks at locaticis far removed from the hainmer-dri!led borehole, but experience from other studies of cores of the same rock (Durham, 1982) indicates that one always seems to identify a few, generally short, fresh cracks even in starting material. The observations from sections 3-6 fall in the same qualitative category so those sections cannot at this point be differentiated from starting material. One reason, in fact, that the precision is poor in these data is simply that there are not many cracks to be seen. The random appearance or disappearance of one crack in a 500X micrograph is typically a $20-50 \%$ perturbation of the number observed. Meaningful jmprovement in the level of precision would require significantly more data, roughly 10 times the current amount.

\section{CONCLUSIONS}

The hammer-drilling process used at SFT-C to bore the $610-\mathrm{mm}$ canister holes has caused some microfracturing to occur in a shell $10-30 \mathrm{~mm}$ wide around the borehole. Beyond $30 \mathrm{~mm}$, the level of microfracturing in the ruck is not distinguishable from background. Any significant improvennent in the precision of these measurements using the current techniques would require a substantial additional effort.

\section{ACKNOW LEDGMENTS}

We thank $M_{*}$ Axelrod for advice and help on statistical aspects of this study, and $R$. Thorpe lor the stress calculations. 


\section{REFERENCES}

Brace, W. F., E. Silver, K. Hadley, and C. Goetze, Cracks and pores: a closer look, Science, (1972) 178, 162-164.

Durham, W. B., Thermal Properties of Climax Stock Quartz Monzonite to $573 \mathrm{~K}$ and 50-MPa Confining Pressure, University of California, Lawrence Livermore NationaJ Laboratory, Report UCRL-53349, Livermore, California, 1982.

Izett, G. A., Granite Exploration Hole, Area 15, Nevada Test Site, Nye County Nevada Test Site, Nye County Nevada--Interim Report, Part C, Physical Properties, Trace Element Memorandum Report 836-C, United States Geological Survey, 1960.

Jones, S. E., D. R. Ries, L. Lyles, A. L. Dittli, and K. W. Johnson, FRAMIS Reference Manual, University of Califernia, Lawrence Livermore National Laboratory, Livermore Computing Systems Document LCSD-554, Livermore, California, May, 1981.

Ramspott, L. D., L. B. Ballou, R. C. Carison, D. N. Montan, T. R. Butkovich, J. E. Duncan, W. C. Patrick, D. G. Wilder, W. G. Brough, and M. C. Mayr, Technical concept for a test of geological storage of spent reactor fuel in the Climax granite at the Nevada Test Site, University of California, Lawrence Livermore National Laboratory, Report UCRL-52796, Livermore, California, 1979.

Thorpe, R. K., personái communication, September, 1982.

Wilk, M. B. and R. Gnanadesikan, Probability plotting methods for the analysis of data, Bionetrika (1968), 55, 1 .

$2046 \mathrm{x}$ 
Table 1. Average Crack Length ( $l$ ) vs. Distance from Center of the Borehole (R)

\begin{tabular}{cccr} 
& & Set I & Set 2 \\
Section No. & R, mm & $\ell, j \mathrm{~m}$ & $\ell, \mu \mathrm{m}$ \\
\hline & 310 & $-\cdots$ & 35 \\
3 & 309 & 27 & 29 \\
4 & 368 & 11 & 24 \\
5 & 220 & 23 & 10 \\
6 & 368 & $-\cdots$ & 26 \\
& 334 & 18 & 22
\end{tabular}




$$
-10-
$$

Table 2. Average Number of Cracks/Unit Area (n) vs. Distance from Center of the Borehole (R)

$\begin{array}{cccc} & & \text { Set I } & \text { Set 2 } \\ \text { Section No. } & \text { R, mm } & \mathrm{n} / \mathrm{mm}^{2} & \mathrm{n} / \mathrm{mm}^{2} \\ 1 & 310 & -\ldots & 143 \\ 2 & 309 & 181 & 96 \\ 3 & 368 & 105 & 63 \\ 4 & 420 & 168 & 39 \\ 5 & 368 & -\cdots & 85 \\ 6 & 334 & 87 & 54\end{array}$


Table 3. Average Crack Length/Unit Area (L) vs. Distance from Center of the Borehole ( $R$ )

$\begin{array}{cccc} & & \text { Set } 1 & \text { Set } 2 \\ \text { Section No. } & \mathrm{R}, \mathrm{mm} & \mathrm{L}, 1 \mathrm{~m} / \mathrm{mm}^{2} & \mathrm{~L}, \mathrm{~mm} / \mathrm{nm}^{2} \\ 1 & 310 & - & 5010 \\ 2 & 309 & 4930 & 3070 \\ 3 & 368 & 1130 & 1690 \\ 4 & 420 & 3890 & 560 \\ 6 & 368 & - & 2250 \\ 6 & 334 & 1730 & 1430\end{array}$


Table 4. Average of the Natural Logarithm of the Crack, Length (In(l)) vs. Distance from Center of the Borehole (R)

Set I

\begin{tabular}{|c|c|c|c|c|c|c|}
\hline Section No. & $\mathrm{R}, \mathrm{m} n$ & $\overline{\ln (l)}$ & S.D. & S.E. & $\overline{\ln (\ell)}$ & S.D. \\
\hline 1 & 310 & --- & ---- & --- & 3.168 & .987 \\
\hline 2 & 309 & 2.917 & .865 & .106 & 2.908 & 1.046 \\
\hline 3 & 368 & 2.298 & .403 & .068 & 2.958 & .787 \\
\hline 4 & 420 & 2.859 & .777 & .104 & 2.444 & .649 \\
\hline 5 & 368 & - & --- & -- & 2.960 & .788 \\
\hline 6 & 334 & 2.65 .3 & .823 & .153 & 2.647 & .977 \\
\hline
\end{tabular}

S.E. $=$ Standard Error $=$ Standard Deviation $/ \sqrt{\mathrm{N}}$

$\mathrm{N}=$ No. of cracks in each section 


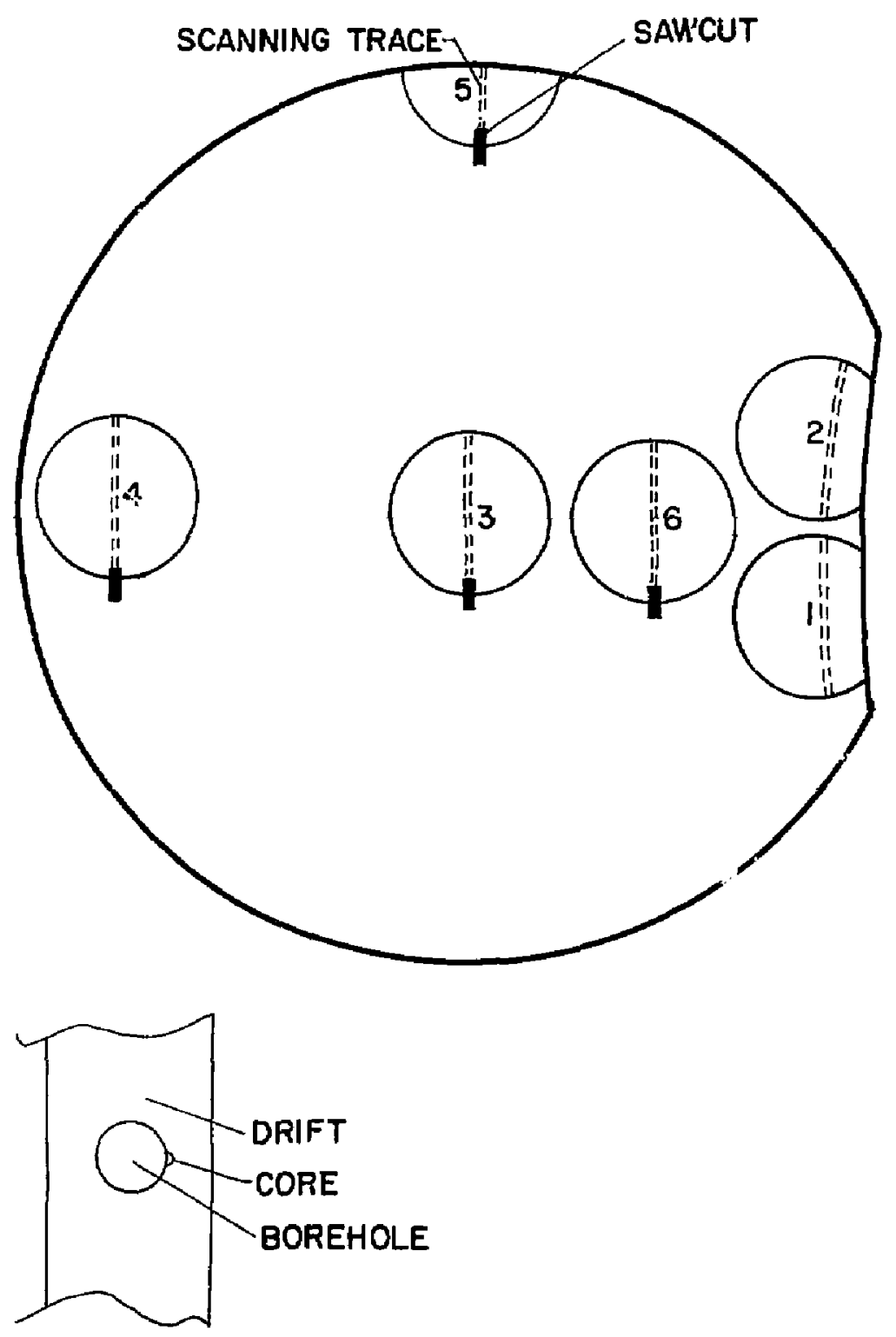

Fig. I. Sample locations in the 140-mm core. 
Fig.2. Illustrative example of the identification of cracks as "fresh" or "old". Figs. 2(a) and 2(b), SEM inicrographs from Set. 1. Figs. 2(c) and 2(d), tracings, on the same scale as $2(a)$ aidd $2(b)$, of cracks considered fresh. Old cracks have characteristic irregular edges which do not match each other wel! (such as those labeled $\mathrm{A}$ in 2(a), (b)), or have bridges of healing material and rounded tips (such as those labeled B). In Fig. $2(a)$, the lighter phase at the right-hand side is plagioclase and the remaining darker phase is quartz. In Fig. 2(b) the lighter phase in the lower left is orthoclase and the darker phase is plagiochlase. The bar represents a length of $100 \mathrm{~mm}$. 


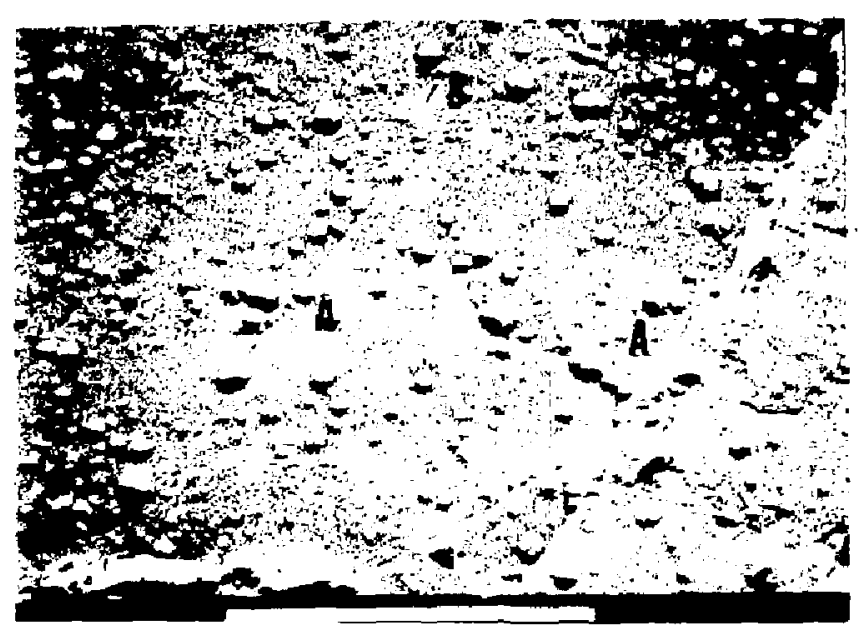

Fig. 2(a)

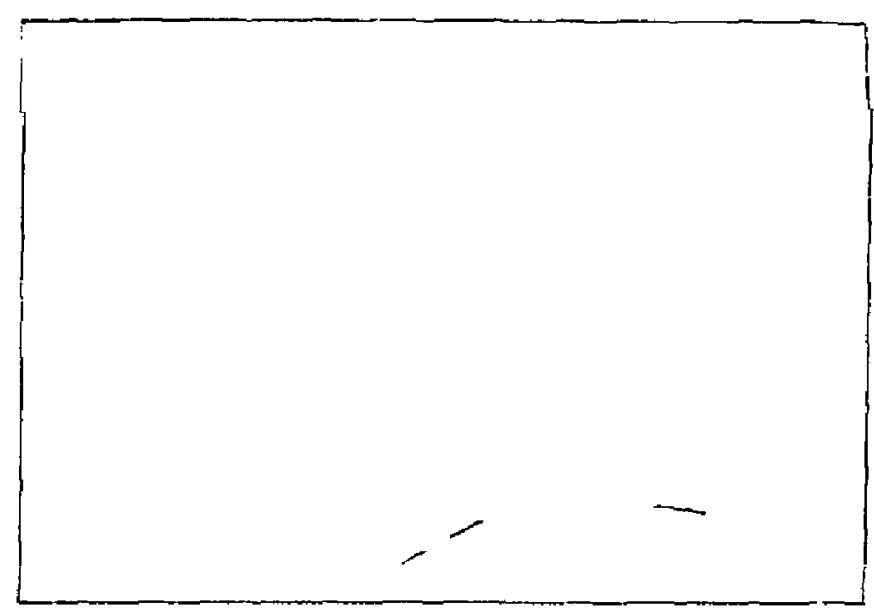

Fig. 2(c) 


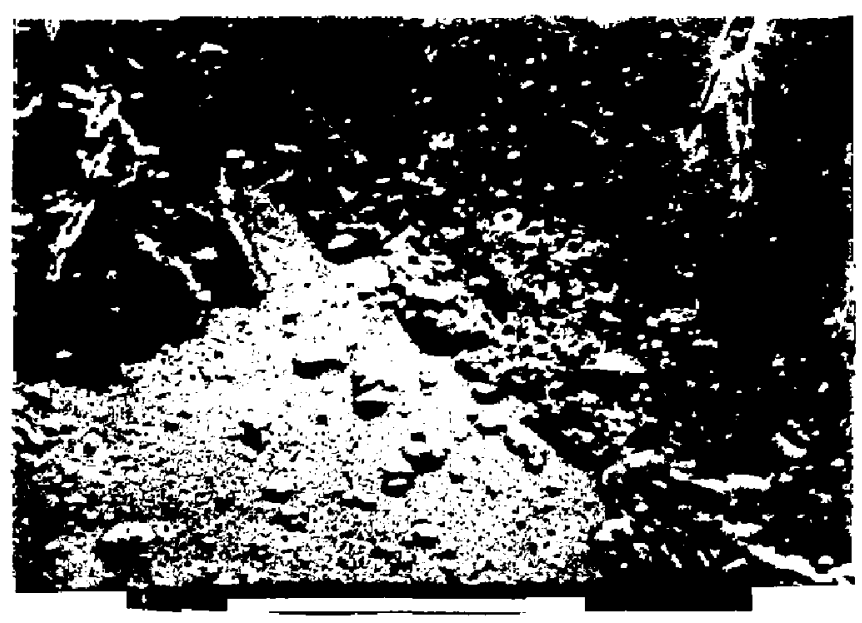

Fig. 2(b)

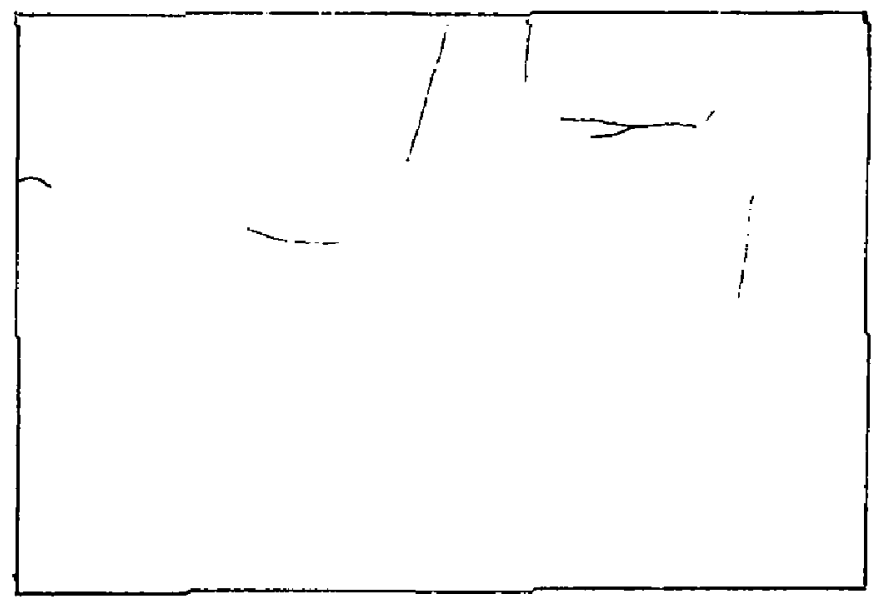

Fig. 2(d) 


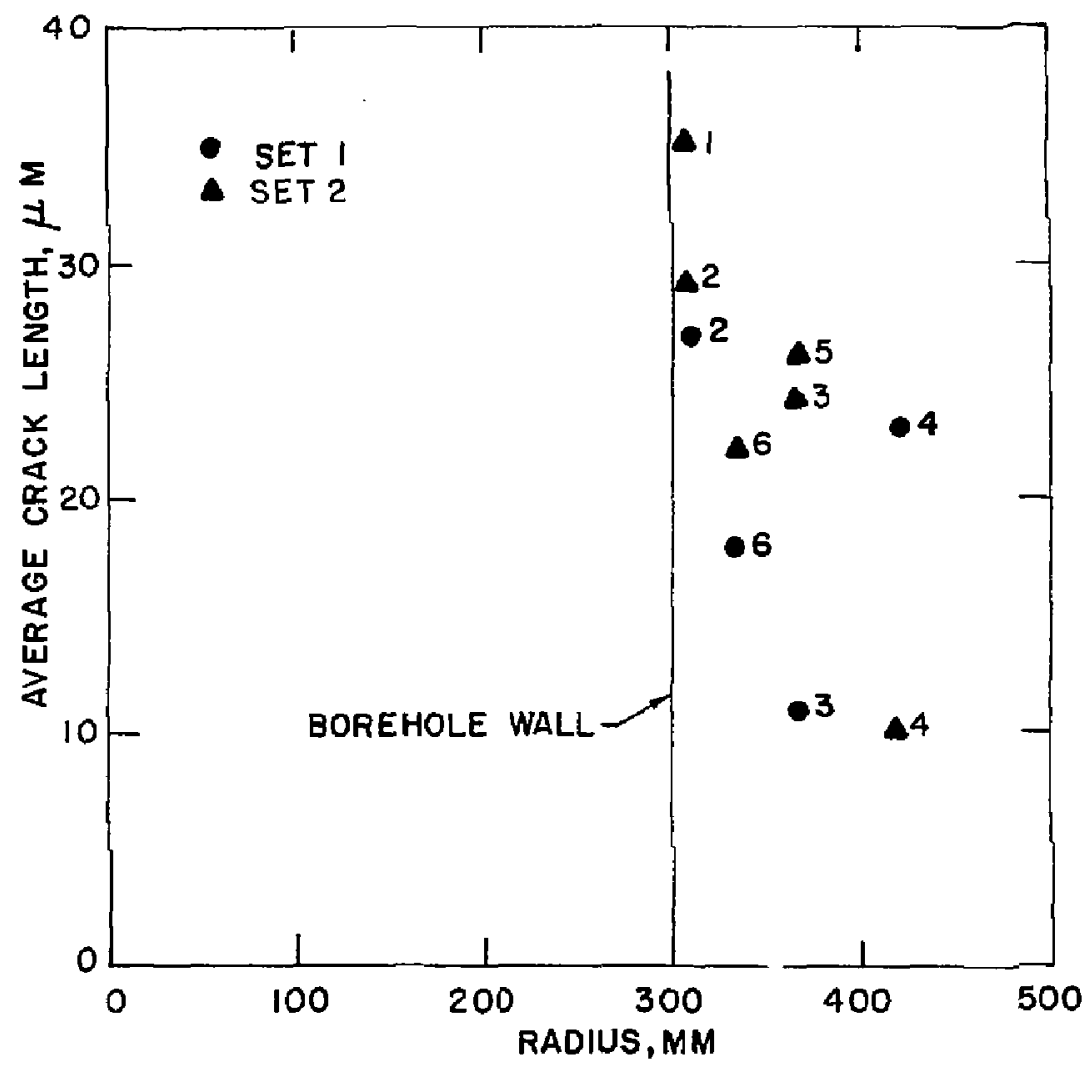

Fig. 3. Average crack length vs. radius 


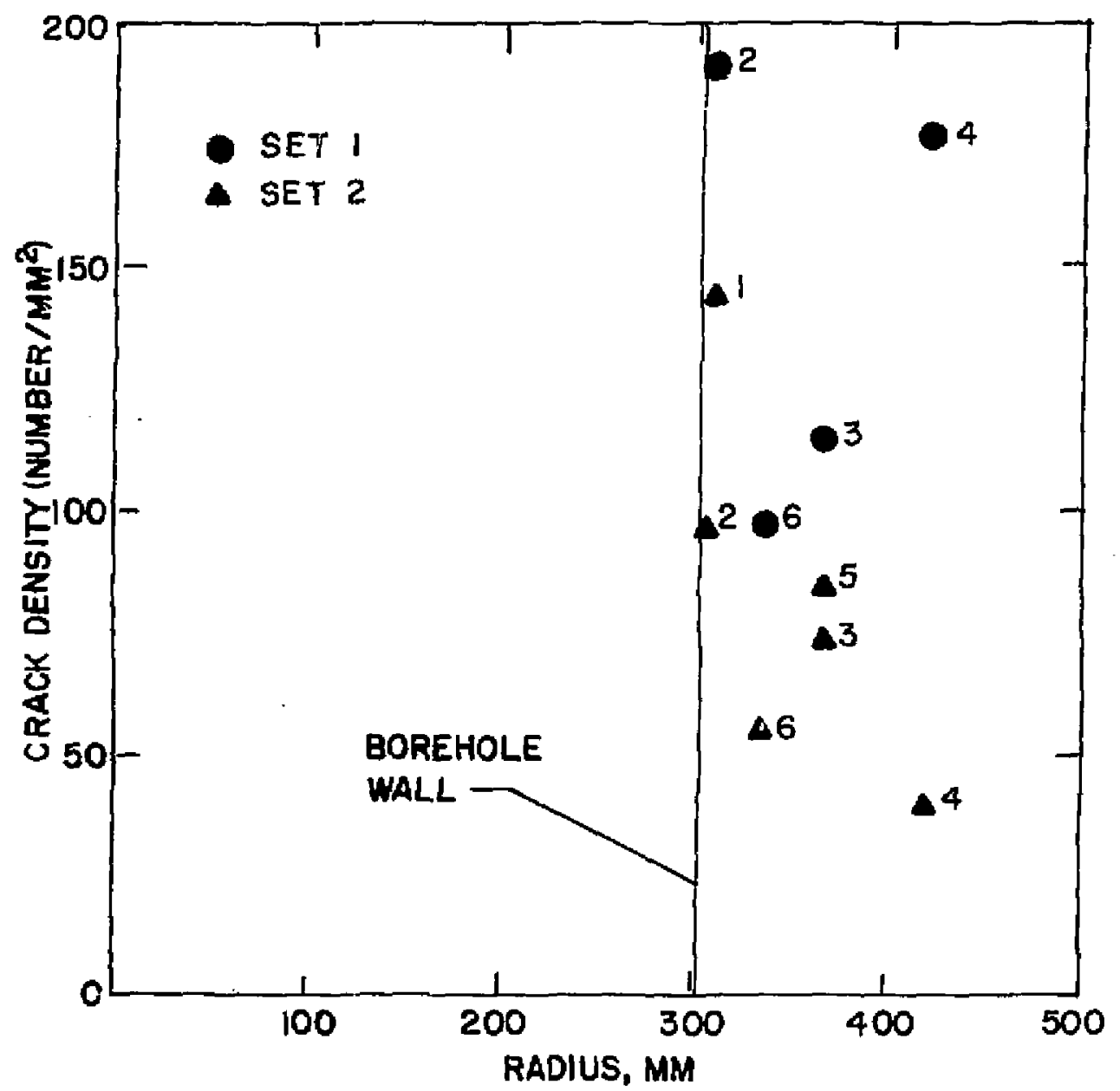

Fig. 4. Crack density vs. radius. 


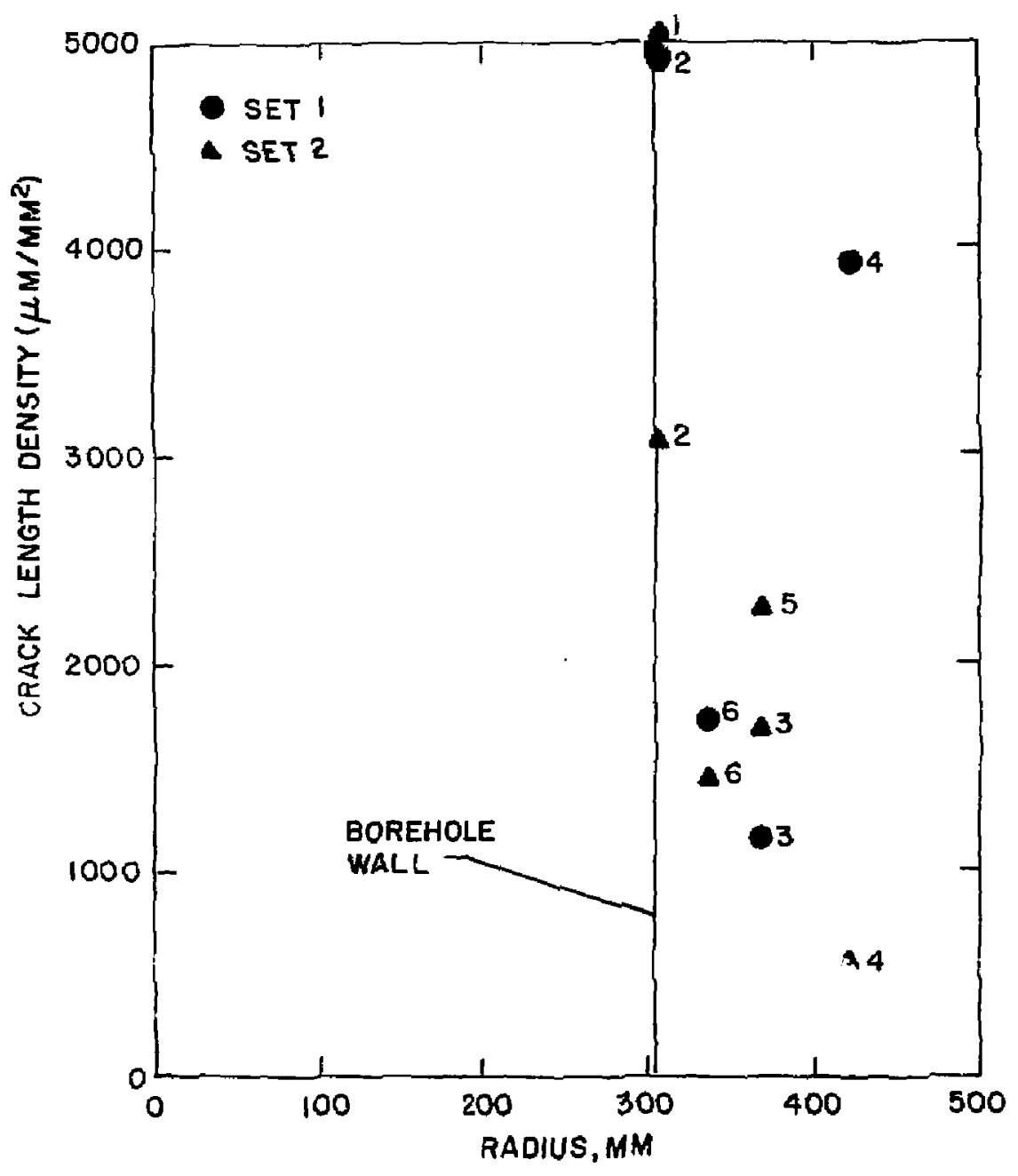

Eig. 5. Crack length density va. radius. 


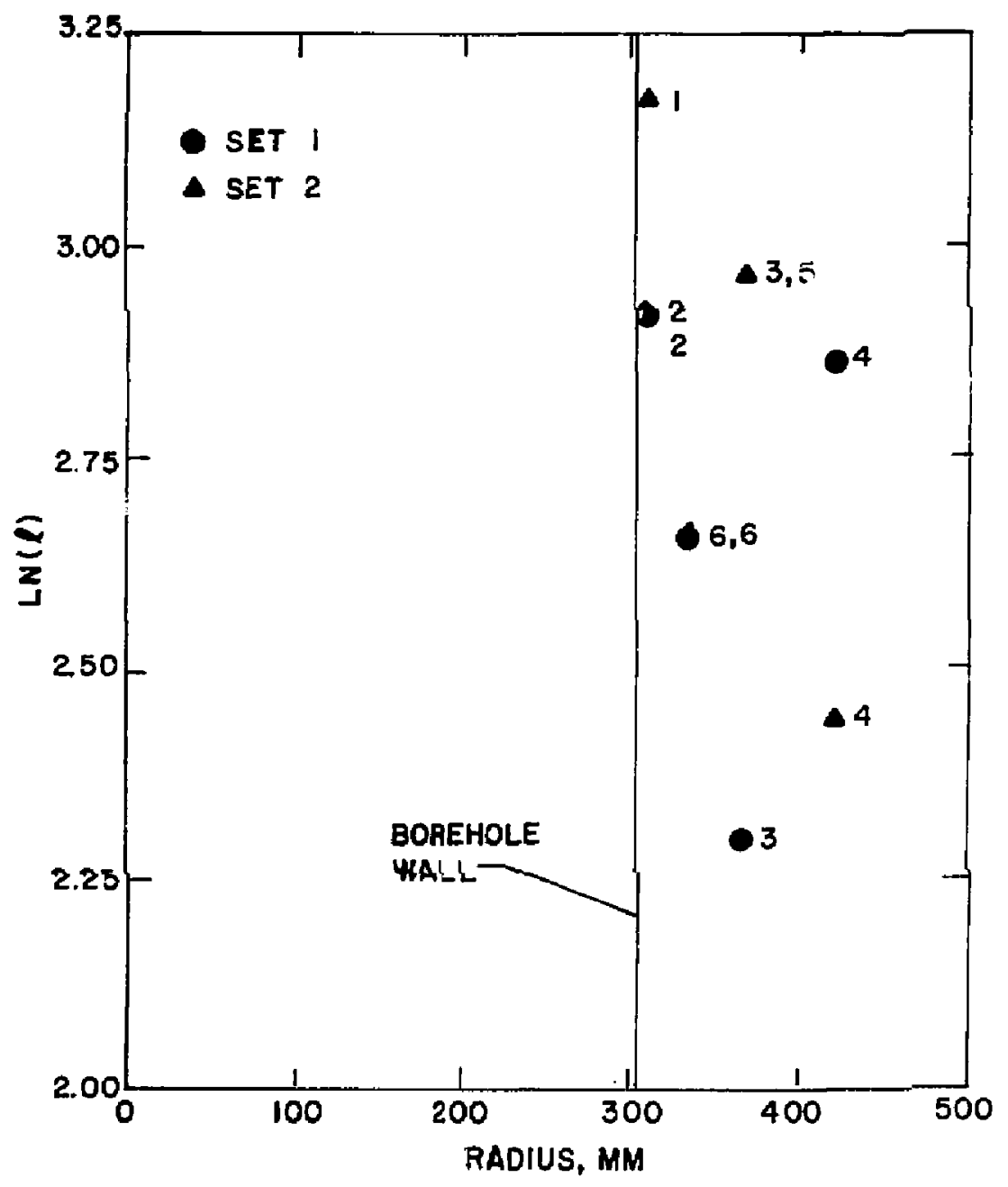

Fig. 6. Average natural logarithm of the crack length us. radils. 


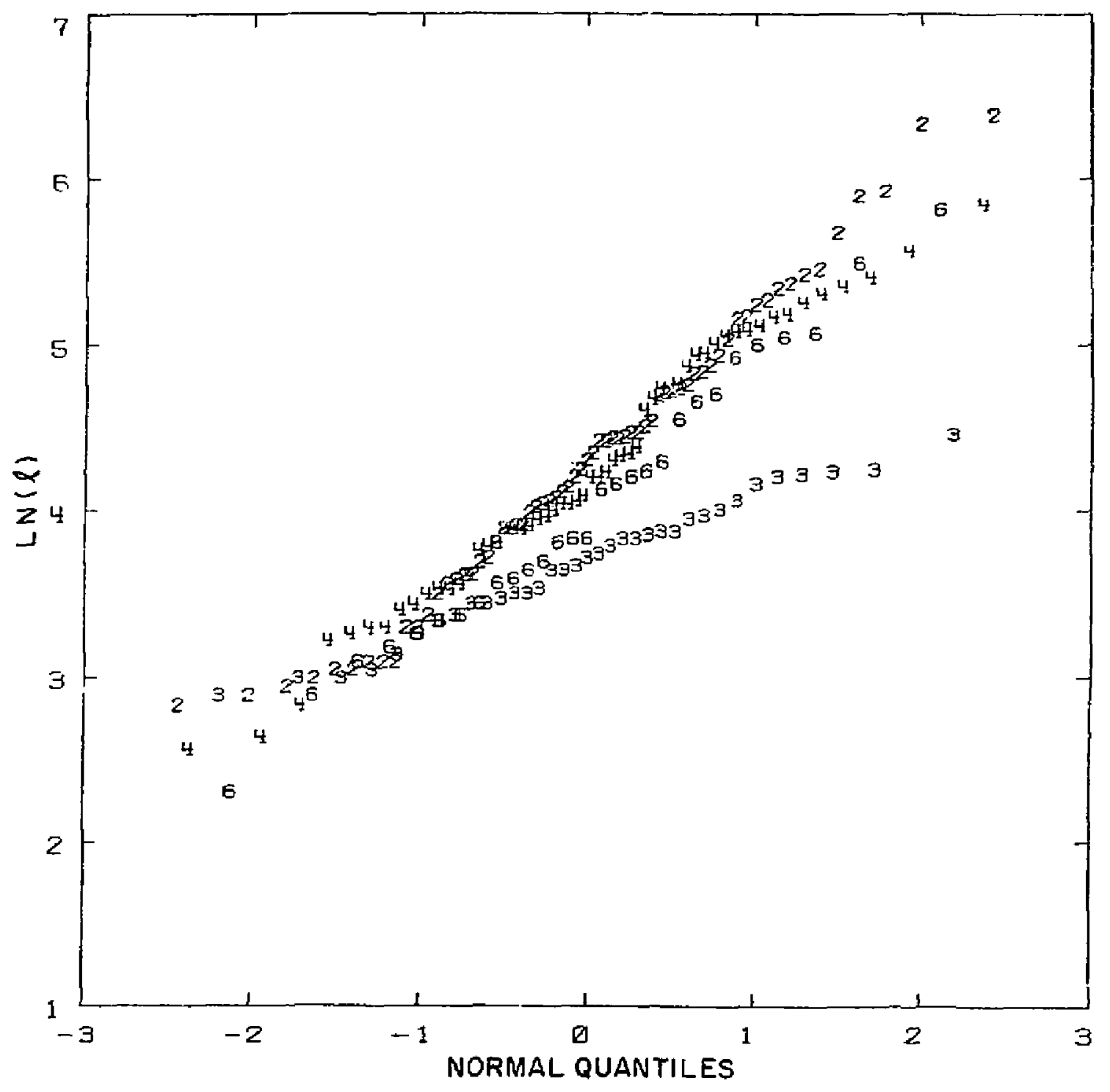

Fig. 7(a). Probabtlity plot, Set 1 , Sections 2-4, 6 . 


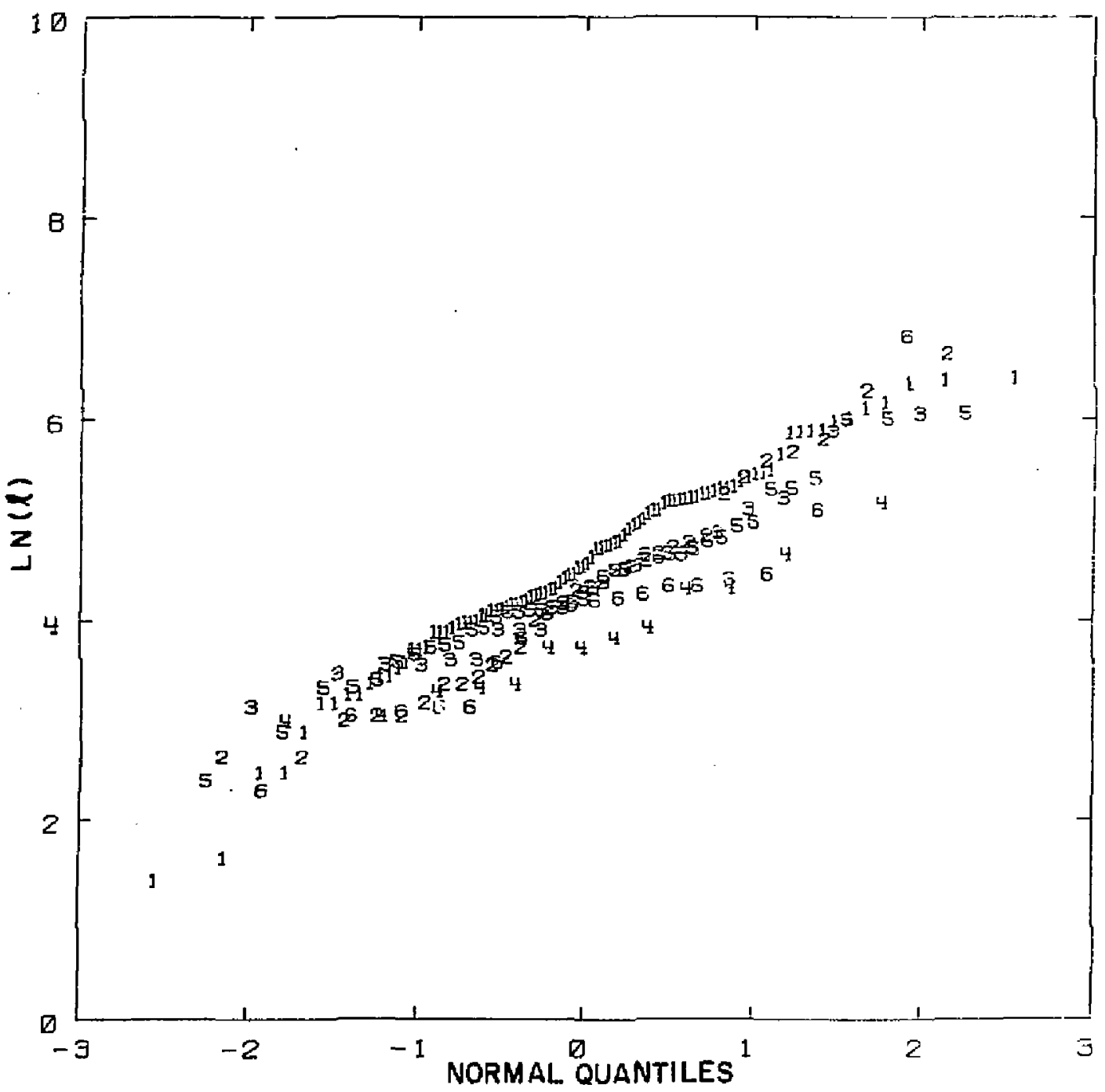

Fig. 7(b). Probability plot, Set 2, Sections 1-6. 


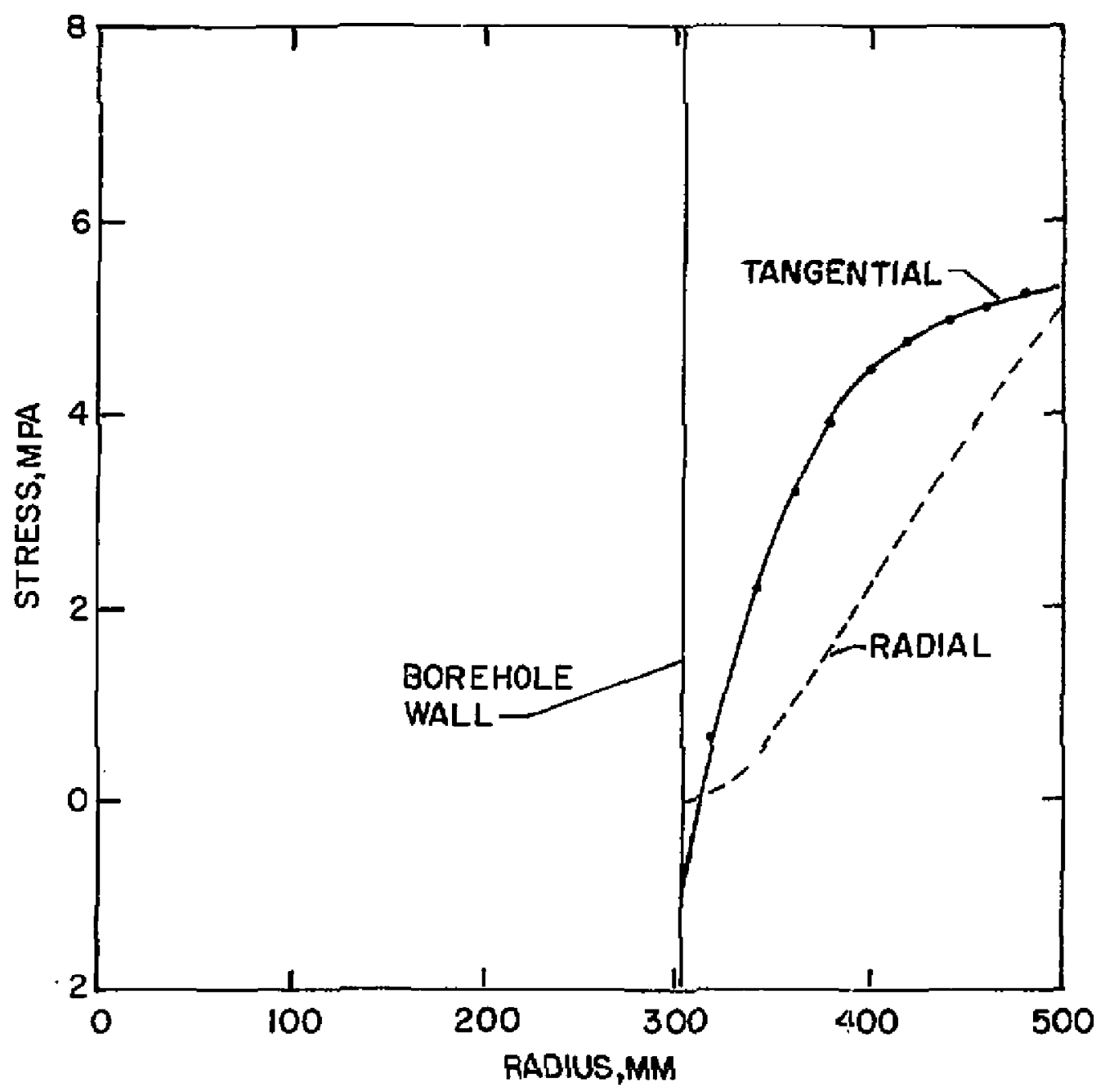

Fig. 8. Calculated stress vs. radius. 